\title{
A IMPORTÂNCIA DA OBRA E DA ATUAÇÃO POLÍTICA DE JOAQUIM NABUCO PARA A CONSTRUÇÃO DA CULTURA JURÍDICA CONTEMPORÂNEA
}

\author{
Helano Márcio Vieira Rangel* \\ Eveline de Castro Correia*
}

\section{RESUMO}

O estudo enfoca a obra de Joaquim Nabuco em sua prática abolicionista, monárquica e panamericana. Há rara literatura que analise o seu trabalho e a cultura jurídica contemporânea, razão pela qual se justifica o presente ensaio. O objetivo principal do trabalho é, assim, analisar a obra e militância política de Joaquim Nabuco, a fim de demonstrar a sua importância para a construção contemporânea do Direito Constitucional e do Direito Internacional. Conclui-se que a cultura jurídica contemporânea se deve, em parte, ao esforço de homens como Nabuco, o qual se devotou à causa abolicionista. Trata-se de pesquisa explicativa, qualitativa e bibliográfica.

PALAVRAS-CHAVE - Joaquim Nabuco; abolicionismo; cultura jurídica; monarquia; direitos humanos.

\section{THE IMPORTANCE OF JOAQUIM NABUCO'S WRITINGS AND POLITICAL PERFORMANCE FOR THE CONSTRUCTION OF CONTEMPORARY JURIDICAL CULTURE}

\section{ABSTRACT}

The analysis focuses the work of Nabuco in his abolitionist, monarchist and Pan-American practice. There is rare literature that analyzes his legacy and the contemporary juridical culture, reason why the current paper justifies itself. The main purpose of this essay is, thus, analyze Nabuco's writings and political performance in order to demonstrate his importance to the contemporary construction of Constitutional and International Law. The paper concludes that the contemporary juridical culture came to happen, in part, due to the effort of men like Nabuco, whom acted with devotion to the abolitionist cause. The research is explicative, qualitative and bibliographical.

KEYWORDS - Joaquim Nabuco; abolitionism; juridical culture; monarchy; human rights

\section{INTRODUÇÃO}

Joaquim Nabuco notabilizou-se como uma das mais célebres personalidades do final do século XIX e começo do século XX, tanto sob a perspectiva jurídica como política.

\footnotetext{
* Mestre em Ordem Jurídica Constitucional (Universidade Federal do Ceará), advogado, professor titular I do Centro Universitário Estácio do Ceará, titular da cadeira de n.15 da Academia Brasileira de Cultura Jurídica (ABC Juris) que tem como patrono Joaquim Nabuco.

* Mestra em Direito Constitucional (Universidade de Fortaleza), advogada, professora titular I do Centro Universitário Estácio do Ceará.
} 
Nascido em Recife, filho da mais abastada elite nordestina em meados do Século XIX, sua vasta obra notabiliza-se por seu cunho social e monarquista, tendo adotado uma postura panamericana já na derradeira fase de sua vida.

Joaquim Nabuco foi um homem à frente de seu tempo e decisivamente modificou o panorama político e jurídico brasileiro. As questões que se colocam, no entanto, são: a vida e obra de Joaquim Nabuco teriam algum impacto na cultura jurídica atual? Caso positivo, qual seria ele e qual o sentido? Tais são os problemas centrais que norteiam a vertente pesquisa.

A pesquisa justifica-se como forma de resgatar a vida e obra de Joaquim Nabuco, o qual já conta com inúmeros estudos sobre suas obras, sob um prisma histórico, sociológico e antropológico, mas com carências de fontes a partir de uma perspectiva jurídica.

A pesquisa dividiu-se em três capítulos: o primeiro capítulo (segundo tópico) traça uma breve biografia de Joaquim Nabuco, com ênfase em sua formação e obras principais. Analisam-se os estudos de Nabuco, primeiramente em São Paulo e, após, na renomada Faculdade de Direito de Recife, assim como sua estadia nos Estados Unidos e Inglaterra após a formatura. Disserta-se ainda sobre sua notável trajetória acadêmica nos Estados Unidos, quando se tornou Doutor honoris causa em Letras pela Universidade de Yale. Faz-se ainda ampla revisão de sua obra e análise de sua derradeira fase, como professor num período republicano.

O segundo capítulo (terceiro tópico) disserta sobre a atuação política e institucional abolicionista de Nabuco no Império, com enfoque na sua relação com os abolicionistas britânicos, num contato que representava uma tentativa consciente de sabotar a escravidão no Brasil, a partir da pressão externa representada pelo Império Britânico. Analisa-se como a obra de Nabuco aspirava não apenas a uma mera e formal libertação dos escravos, mas buscava simultaneamente resgatar o constrangimento do passado e projetar um olhar para o futuro, com a defesa dos Direitos Humanos ainda em época de vanguarda. Examina-se ainda a vitória de seu movimento abolicionista, porém ao grande custo da queda da monarquia, o ocaso político inicial de Nabuco, que manteve inicialmente a defesa da monarquia e sua reconciliação com o regime republicano, com a aceitação de convite para exercer o cargo de embaixador do Brasil nos Estados Unidos. 
O derradeiro e principal capítulo (quarto tópico) ressalta a importância da obra de Nabuco para a construção de uma cultura jurídica brasileira contemporânea, especialmente nos campos do Direito Constitucional e do Direito Internacional. Teoriza-se sobre como Nabuco advoga a submissão das leis brasileiras às normas internacionais sobre liberdades pessoais e a flagrante ilegalidade da escravidão no Brasil. Analisam-se temas na obra de Nabuco que lançaram luzes para a afirmação histórica do princípio da dignidade da pessoa humana até a sua consagração na Constituição Federal de 1988. Enfoca-se ainda o alinhamento do pensamento de Nabuco com a cultura liberal e capitalista da época e sua aspiração de transformar o Brasil numa poderosa nação nos moldes dos Estados industriais mais desenvolvidos do período oitocentista.

Quanto à metodologia, trata-se de uma pesquisa explicativa, qualitativa e construída a partir de referências bibliográficas.

\section{UMA BREVE BIOGRAFIA DE JOAQUIM NABUCO}

Joaquim Aurélio Nabuco de Araújo nasceu em 19 de agosto de 1849 em Recife, Pernambuco. Filho de família aristocrática ${ }^{1}$, Nabuco foi criado até os oito anos por sua madrinha Dona Ana Rosa no engenho Massangana, vindo a mudar-se em 1857 para a casa da família no Rio de Janeiro. Nessa época, a carreira administrativa e política eram construídas a partir de uma educação pessoal voltada aos costumes e tradições em seletas famílias do Império. (OLIVEIRA, 2013)

Em 1869, o jovem Nabuco, não obstante ter começado a estudar em São Paulo, passa a estudar na renomada Faculdade de Direito de Recife. Como ressalta Alonso (2007), esse costume era uma tradição entre famílias aristocráticas que visava a colocar o aspirante à vida política em contato com as duas metades discrepantes do Império, o Norte e o Sul.

Após a formatura, Nabuco permaneceu de 1876 a 1878 entre Estados Unidos e a Inglaterra, em cargos diplomáticos. Aclimatou-se então com a cultura abolicionista da época. Os americanos o ensinaram que o extremo e o radicalismo devem ser evitados, pois podem

\footnotetext{
${ }^{1}$ Segundo preconiza Alonso (2002, apud OLIVEIRA, 2013, p.27), em que pese ser Joaquim Nabuco filho do senador Nabuco de Araújo e de Ana Paes Barreto, da tradicional família Suassuna, ele não vinha de uma aristocracia "sangue azul", ou seja, da abastada classe latifundiária. De fato, Nabuco provinha de uma aristocracia burocrática sem lastro financeiro, porém influente pois conectada vivamente à política imperial.
} 
resvalar em guerra civil. Na Inglaterra, conheceu o costume das mudanças evolutivas calcadas no suporte de uma consciência pública organizada, o que deveria ser seguido. Aos 30 anos, Nabuco trouxe essas ideias no retorno compulsório ao Brasil, ao ser eleito deputado, em 1879, por força da derradeira vontade de seu pai. (ALONSO, 2010)

Como assevera Souza (2011), Joaquim Nabuco foi jurista, político, diplomata e escritor - um dos fundadores da Academia Brasileira de Letras, sendo considerado uma das mais renomadas personalidades de seu tempo, ao lado de figuras como Clóvis Beviláqua, Teixeira de Freitas e Ruy Barbosa ${ }^{2}$. Com a Proclamação da República, retirou-se da vida pública, retomando-a dezesseis anos depois, somente para servir na Embaixada Brasileira dos Estados Unidos da América, desde 1905.

Doutor em Direito pela Universidade de Columbia e Doutor Honoris Causa em Letras pela Universidade de Yale (1908), o poeta-embaixador Nabuco sempre viveu, durante sua estada na América, circundado por títulos e reconhecimentos. Como pondera Cândido (1985 apud JACKSON 2008), a Universidade de Yale, ao ter-lhe concedido tal honraria acadêmica, talvez não tenha percebido que sacramentava o elo entre o literário e o político que perpassava membros da elite intelectual brasileira desde antes da Independência. Ao escolher como tema para sua primeira conferência perante os alunos de Yale "O lugar de Camões na literatura", Nabuco enfatiza a sua predileção pelo gênero literário, apresentando à audiência um alto nível estético de língua e literatura, a partir de uma perspectiva ligada ao alto conceito de cultura, classicismo e universalismo da expansão marítima lusitana. (JACKSON, 2008)

Na biografia de Nabuco, escrita pela própria filha Carolina Nabuco, descreve-se o porquê de o poeta-embaixador ter uma ligação com a academia como um meio para expor suas ideias e teorias. Para ele, falar à mocidade acadêmica americana era um consolo de não poder dirigir-se à mocidade brasileira, nos últimos anos de vida. Assim, o seu espírito apostólico lhe dera na velhice o amor ao magistério, a ambição inesgotável de falar longamente a jovens pupilos antes que a morte o levasse. Tal se encontra registrado numa carta de 1909. Para Nabuco a glória suprema era a de formar discípulos, uma vez que

\footnotetext{
${ }^{2}$ É interessante observar as argutas lições de Souza (2011) no sentido de que Ruy Barbosa é a exata antítese de Joaquim Nabuco, uma vez que aquele nunca acreditou no regime monárquico, mas sim no presidencialismo republicano, dando foco ainda à federação como elemento garantidor da democracia plena. Desse modo, suas lições serviram de base ideológica para a Constituição de 1891 .
} 
renasceria a partir de suas ideias em outra geração e, assim, daria continuidade à prestação de serviços à nação. (NABUCO, 1928)

Tais características o destacavam como um filho brasileiro da maior envergadura. A sua vida foi de grande valia para romper os paradigmas com a retrógrada e obsoleta cultura escravocrata brasileira, de modo que suas inestimáveis lições ecoaram ainda profundamente no coração e mente dos norte-americanos, os quais ainda se recordavam dos estigmas e traumas da Guerra da Secessão. Tal confronto, como é cediço, orbitou em torno de uma cultura abolicionista e industrial nos Estados do Norte versus uma cultura escravocrata e latifundiária nos Estados do Sul.

Nesse sentido, em sua densa obra, Nabuco faz detalhada análise histórica de movimentos contrários à escravidão no Brasil desde o período anterior à Independência e toda a evolução da luta abolicionista ao longo do século XIX. É interessante observar que Joaquim Nabuco austeramente manteve sua inclinação monárquica, mas era crítico de várias práticas do Governo Imperial, especialmente a manutenção da escravidão, a qual atribuía como responsável por grande parte dos problemas brasileiros.

Defendia, assim, a supressão da escravidão como primeiro ato de consenso político. Para atingir tal objetivo, todavia, era contrário às manifestações públicas ou rebeliões populares contra a escravidão, pois estava convencido de que o abolicionismo deveria partir do parlamento - como ato político e consciente - e não das ruas. (SOUZA, 2011)

Estão entre as suas obras: 1) Camões e os Lusíadas (1872), 2) L'amour est Dieu (1874), 3) O Abolicionismo (1883), 4) Campanha abolicionista no Recife (1885), 5) O erro do Imperador (1886), 6) O Eclypse do Abolicionismo (1886), 7) Escravos (1886), 8) Por que continuo a ser monarquista (1890), 9) Balmaceda (1895), 10) O dever dos monarquistas (1895), 11) A intervenção estrangeira durante a revolta (1896), 12) Um estadista do Império (1897-1899), 13) Minha formação (1900), 14) Escritos e discursos literários (1901), e 15) Pensées detachées et souvenirs (1906). Em organizações post mortem estão disponíveis as seguintes obras: 1) Discursos e conferências nos Estados Unidos (1911) e 2) Obras completas (1947-1949) 
A trajetória biográfica de Nabuco pode ser bem compreendida a partir de sua morte. Afirma-se que ele morreu três vezes: primeiro morreu o embaixador do Brasil nos Estados Unidos. Na ocasião fora velado pelo Presidente William Taft, o secretário de Estado Philander Knox, juízes da Suprema Corte, senadores, deputados e damas da alta sociedade. Na capital do Império, morria pela segunda vez, agora na forma de intelectual monarquista. Ao seu encontro foram a Academia Brasileira de Letras, que teve em Nabuco o seu secretário vitalício, Graça Aranha, políticos influentes, militares, jornalistas e inúmeras pessoas simples; todos prestaram as últimas honras ao intelectual. O abolicionista morreu em Recife, onde marinheiros descendentes dos escravos que ele inspirou à libertação, o desembarcaram do vapor Carlos Gomes. A cidade natal se despediu de seu filho carregando-o por praças cobertas por multidões até o teatro Santa Isabel, onde se encontravam hasteadas todas as bandeiras de associações abolicionistas. (ALONSO, 2007)

Em virtude de sua inestimável projeção para o presente e o futuro das letras jurídicas, Joaquim Nabuco tornou-se patrono da cadeira de número 15 da Academia Brasileira de Cultura Jurídica, uma justa homenagem à sua história e vida.

\section{A ATUAÇÃo POLÍticO-ABOLICIONISTA DE NABUCO NO IMPÉRIO E SUA POSTERIOR CARREIRA DIPLOMÁTICA NOS EUA}

A tradição abolicionista de Joaquim Nabuco deriva de nítida influência paterna. $O$ senador Thomaz Nabuco foi um dos poucos políticos da época que combatiam abertamente o tráfico de pessoas e a escravidão. Durante sua passagem pelo Ministério da Justiça (18531857), reprimiu duramente as últimas tentativas de importar escravos, as quais eram penalmente tipificadas desde a Lei Eusébio de Queirós (1850). Nos anos de 1860, foi a pedra angular da primeira legislação voltada para a abolição da escravidão no Brasil, a Lei do Ventre Livre (1871).

Em 1865, o imperador Dom Pedro II incumbiu ao jurista e senador Pimenta Bueno a missão de produzir o esboço de uma legislação abolicionista. Em janeiro de 1866, o senador apresentou cinco anteprojetos, entre os quais se destacava o da libertação dos nascituros. Foram levados logo a seguir ao gabinete chefiado pelo marquês de Olinda, onde não encontraram apoio. A razão (ou desculpa) principal apresentada para a resistência foi a de que o Brasil estava envolvido na guerra contra o Paraguai. (BETHELL; CARVALHO, 2009) 
O Brasil ostentou a condição de país escravocrata durante a maior parte do século XIX, enquanto inúmeros países promoveram esta libertação décadas ou anos antes, em que pesem os esforços da família Nabuco entre outros poucos abolicionistas entre as fileiras burocráticas do Estado.

Enquanto o senador Thomaz Nabuco se engajava na causa abolicionista no Senado e no Conselho de estado, o filho Joaquim Nabuco convivia em São Paulo com o famoso poeta Castro Alves que empolgava as plateias ao recitar seus versos abolicionistas. O ambiente estudantil era francamente hostil à escravidão. Em 1869, Nabuco mudou-se para a Faculdade de Direito do Recife, ambiente bem mais arredio às ideias abolicionistas. (BETHELL; CARVALHO, 2009)

Um dos aspectos mais obscuros da obra de Nabuco em sua luta contra a escravidão é a sua relação com os abolicionistas britânicos. Essa relação em geral aparece como algo secundário, mas as 110 cartas trocadas entre ambos indicam algo diferente. $\mathrm{O}$ contato significou uma parceria consciente entre Nabuco, representante da elite política vanguardista brasileira e a elite britânica do Reino Unido, centro do Império econômico e poder mundial na época, numa exitosa tentativa de minar o escravismo no Brasil. (BETHELL; CARVALHO, 2009)

Desse modo, é possível afirmar que Nabuco representou um suporte interno para a política exterior britânica, a qual, por razões econômicas ligadas à difusão do capitalismo industrial, enxergava no instituto da escravidão um imenso obstáculo às suas pretensões. Sua visão transcendia a estreita obediência à Coroa Brasileira e também ia além de rasas noções de patriotismo nacionalista. Sua causa abolicionista ocupava a centralidade de sua atividade política e autoral, abalando as vetustas estruturas oligárquicas e escravistas da elite ruralista brasileira no século XIX.

Assim, Nabuco firmou parceria com a Anti Slavery Society, a qual funcionou perfeitamente para dar à causa abolicionista uma dimensão internacional, aumentando a pressão sobre o governo e os escravocratas brasileiros. Acusado de antipatriota por envergonhar o Brasil no exterior ao expor as chagas da escravidão, Nabuco defendia-se afirmando que não poderia prestar maior serviço à nação ao estimular o mundo inteiro a 
repudiar a escravidão, pois tal posição ecoaria no país, ajudando-o a resgatar a liberdade e alcançar o nível de civilização já atingido por outros povos. (BETHELL; CARVALHO, 2009)

Aliás, conforme análise percuciente de Alonso (2010), Nabuco inseriu o movimento abolicionista brasileiro numa rede abolicionista transnacional. A análise da professora Alonso é no sentido de que a trajetória de Joaquim Nabuco engatou uma franca relação não só com ingleses, mas com norte-americanos, franceses, cubanos, porto-riquenhos e até filipinos. Operou o que se conceitua na literatura sobre redes sociais de brokerage, pois se filiou a várias redes abolicionistas e mediou intercâmbios entre elas, contribuindo sobremaneira para catalisar o fim da escravidão no Brasil.

Nabuco não almejava uma mera e formal libertação dos escravos, o seu projeto político era, ao mesmo tempo, um resgate do passado e um olhar para o futuro. Sua visão de vanguarda já defendia direitos humanos e de inclusão social muito antes das primeiras Constituições sociais em nível internacional, como a Mexicana de 1917 e a de Weimar em 1919, e, por conseguinte, da própria Constituição Brasileira de 1934. É, assim, um inestimável precursor de princípios basilares para o nosso ordenamento jurídico hodierno como o valor social do trabalho, isonomia e dignidade da pessoa humana, alicerces jurídicos da Constituição Federal de 1988.

O abolicionismo, porém, não é só isso e não se contenta com ser o advogado ex
officio da porção da raça negra ainda escravizada; não reduz a sua missão a
promover e conseguir - no mais breve espaço possível - o resgate dos escravos e
dos ingênuos. Essa obra - de reparação, vergonha ou arrependimento, como a
queiram chamar - da emancipação dos atuais escravos e seus filhos é apenas a tarefa
imediata do abolicionismo. Além dessa, há outra maior, a do futuro: a de apagar
todos os efeitos de um regime que, há três séculos, é uma escola de desmoralização
e inércia, de servilismo e irresponsabilidade para a casta dos senhores, e que fez do
Brasil o Paraguai da escravidão. (NABUCO, 2011, p. 5)

Não obstante, imperioso ressaltar que o abolicionista de Recife repudiava um movimento revolucionário de massas e propugnava que todos os procedimentos que conduziriam o Brasil ao fim da escravidão tramitassem pelas vias institucionais do Estado. Desse modo, sua campanha abolicionista possuía nítido caráter elitista. Não se destinava aos quilombos ou fazendas, praças ou ruas das cidades, porém à camada poderosa e governante, de modo a instrui-los sobre o retrocesso e os revezes de se manter a escravidão no Brasil.

Acreditava Nabuco que, desse modo, haveria uma pressão insustentável sobre o Parlamento que, acuado, haveria de revogar a escravidão. Sua agenda política professava a 
liberdade, condição primária para a restruturação do Estado e da economia que catapultariam o Brasil à condição de grande ator geopolítico mundial. (OLIVEIRA, 2013) Tais esforços não foram em vão e, em 13 de maio de 1888, o fruto foi devidamente colhido, como descrevem Bethell e Carvalho (2009, p.221):

Em 8 de maio, o projeto de abolição sem indenização foi apresentado na Câmara.
Nabuco pediu que se formasse logo uma comissão para dar parecer. A comissão
cumpriu rapidamente sua tarefa. O parecer foi aprovado, foi dispensada a impressão
e aprovada urgência para discussão no dia seguinte. No dia 9 , o projeto foi aprovado
em segunda discussão por 83 votos a nove. Nabuco solicitou dispensa de impressão
e de prazo, a fim de que o projeto entrasse em terceira discussão no dia seguinte. No
dia 10 , foi aprovado o projeto em terceira discussão e também sua redação, que foi
encaminhada para o Senado. No dia 11 , foi apresentado no Senado. A pedido de
Dantas, foi nomeada comissão que logo deu parecer favorável, dispensando-se a
impressão. No dia 12 , aprovou-se o projeto em segunda discussão. No dia 13 , em
terceira discussão. Nesse dia, às 15 horas, a regente Isabel assinou no Paço da
Cidade a Lei Áurea, que aboliu a escravidão no Brasil. Composta de dois artigos, foi
a mais curta da história do país.

Todavia, a queda da monarquia e o golpe republicano que se seguiram foram uma dura realidade para Joaquim Nabuco. A abolição da escravidão, que era por ele vista como reabilitação e legitimação do sistema monárquico, além de mola propulsora para o progresso e reformas sociais (trabalho livre, educação universal, federalismo, etc.) não ecoou politicamente em favor do Imperador. Na verdade, para a elite rural oitocentista, a lei que aboliu a escravidão sem indenização representou incalculável prejuízo, desfazendo o apoio dado à Coroa ao longo de décadas. O desfecho foi inevitável: assistiu, assim, atônito e mortificado, a queda da monarquia no meio de uma noite, sem qualquer resistência, pouco mais de um ano e meio após a Lei Áurea.

Nabuco intuiu ser a República incompatível com o ideal de reformas sociais erguidas pelo movimento abolicionista na década de 1880. O clima hostil e de guerra civil que duraria até pelo menos 1895 , adicionados às dificuldades político-institucionais de implantação de um novo regime, geraram obstáculos intransponíveis a qualquer reforma social, de modo a repelir, por conseguinte, todo aquele com ele comprometido. Saiu de cena discretamente, não rompendo de início para dar suporte aos monarquistas remanescentes, mas aos poucos fechando-se na campânula ideológica em que sempre vivera. (NOGUEIRA, 2010) 
Alguns meses após o Golpe Republicano, escreveu um artigo intitulado "Por que continuo a ser monarchista", publicado como carta ao Diário do Comércio em 7 de setembro de 1890. Na missiva, aqui trasladada ipsis litteris, a partir do documento original digitalizado e pertencente ao acervo da Fundação Joaquim Nabuco, revela-se o desalento e o desencanto com que o monarquista pernambucano recebeu a transição:

De facto a republica, moralmente falando, só tem perdido terreno desde 15 de Novembro. Não se verificou sómente que o paiz não estava preparado para ella, mas também, o que é talvez peior, que ella não estava preparada para o governo. Diz-se que ella não tinha homens, é um perfeito engano; ella tinha a seu serviço alem de uma brilhante mocidade para secundal-os, dez vezes mais homens de alto merito do que lhe era preciso para organisar-se democraticamente em todo o paiz. O que ella não tinha era princípios.

$[\ldots]$

Dá-se como signal de madureza da republica a sua facil acceitação. Julgo conhecer bastante as correntes da opinião, as tendencias do sentimento popular, para affirmar que o povo se mantem complemente alheio á chamada adhesão. [...]

Se eu tivesse por ambição na vida ser cidadão de uma republica, ha muito, conforme a liberdade falasse mais á minha imaginação pelo prestigio de uma tradição immemorial ou de um futuro garantido por seculos, eu me teria naturalizado suisso ou norte-americano. Teria assim a certeza de pertencer a uma republica authentica. A minha ambição, porém, era ver a liberdade desenvolvida e aperfeiçoada no meu proprio paiz o mais que nos fosse possível, e para isto eu não podia pensar na republica. A republica nos paizes latinos da America, é um governo no qual é essencial desistir da liberdade para obter a ordem.

A lucidez política de Joaquim Nabuco não passa despercebida. Como poderia um regime como o republicano, fruto de um golpe militar, num país essencialmente agrário e elitista, sem a menor consciência nacional ou do que Savigny chamou de Volksgeist (espírito do povo), gerar o progresso e a execução das reformas sociais e econômicas? O Golpe Republicano, instaurando crise institucional de amplo espectro e duração secular, desfez por completo qualquer sonho de resgate digno da nação brasileira frente à chaga da escravidão.

A cultura elitista e atávica de desprezo às "pessoas de cor" foi reforçada pela própria omissão do Estado Brasileiro em reconhecer e promover a necessária educação sobre o atraso, vexame e ignomínia que a escravidão representa, projetando os tentáculos do racismo e preconceito no vertente século XXI.

Nesse sentido, concorda-se com a arguta análise de Nogueira (2010, p.41) quando defende que,

Como regime político, a República era inferior à Monarquia. No Brasil, mais ainda que nos demais países latino-americanos, ela levaria ao despotismo centralista e ao 
fracionamento nacional, pois lhe faltavam as condições (sociais e humanas) para uma implantação harmoniosa e sustentável: não havia tradições republicanas, experiência acumulada, povo ou nação constituída. Sem essas condições, traduzirse-ia como despotismo, seguindo a maldição que parecera acompanhar sua adoção na América do Sul.

Até hoje vemos as crises periódicas os quais passa a República brasileira, fruto de um fosso histórico entre os poderes constituídos e seus mandatários. Nabuco parece fazer um diagnóstico de longo prazo, pois mesmo após quase cento e trinta anos de República, não temos a mínima estabilidade institucional que garanta minimamente a efetivação dos direitos fundamentais em suas múltiplas dimensões. Em que pese o salto desenvolvimentista brasileiro no século XX que o jactou a uma potência mundial, assim como a reconfiguração social e cultural, uma breve análise de indicadores sociais coloca o Brasil em posições idênticas às mais carentes nações da Terra.

Sentindo a derrocada do monarquismo, Nabuco teria se conciliado com a República apenas nove anos mais tarde quando aceitou a defesa do interesse brasileiro em disputa territorial com a Guiana Inglesa, que lhe fora proposto por Campos Sales. Em agosto de 1900 é nomeado da delegação brasileira em Londres, tornando-se funcionário da República. Cinco anos mais tarde, com a abertura da embaixada brasileira em Washington, Nabuco torna-se o primeiro embaixador do Brasil nos Estados Unidos e enche o seu espírito de uma nova causa: a de construir uma ponte com os Estados Unidos e, assim, fazer o país rever seus tradicionais laços com o Velho Continente. Esta fase, que ele próprio descreveu como pan-americanismo, seria a sua última grande batalha, depois da vitória da causa abolicionista e da derrota da causa monárquica.

\section{A IMPORTÂNCIA DA OBRA DE NABUCO PARA A CULTURA JURÍDICA BRASILEIRA CONTEMPORÂNEA}

Como pondera Oliveira (2009), Joaquim Nabuco ocupa lugar preeminente entre os intérpretes do Brasil, uma vez que suas obras se tornaram leitura obrigatória para a compreensão da sociedade e cultura brasileiras, além de influenciar toda uma geração de historiadores e políticos desde o século XIX. 
A obra de Nabuco pode ser dividida em três períodos: o abolicionismo (década de 1880); o monarquismo (década de 1890) e o pan-americanismo (década de 1900). A maior fase, é, indubitavelmente, a abolicionista. O Joaquim Nabuco de "Discursos parlamentares", "O abolicionismo", a "Campanha abolicionista do Recife" e "o Erro do Imperador" o colocam no panteão dos intelectuais que mais influenciaram a história e a cultura brasileiras, tendo a academia o exaltado à condição de precursor do pensamento social brasileiro. (LYNCH, 2012)

Durante os anos 80 do século XIX, o trabalho abolicionista de Joaquim Nabuco não encontrou paralelo em qualquer outro intelectual do período. Era obsessivo, focado, determinado em utilizar tudo a seu alcance para cumprir a sua meta abolicionista, mesmo que isso minasse a monarquia que tanto defendia como forma de governo. "Eu, porém, não fiz da abolição uma coisa, e não estou fazendo outra, por prazer, nem por vocação de apostolo, mas por dever, obedecendo ao simples imperativo categórico da minha Nacionalidade, ao facto unicamente de ser Brazileiro; e como eu há tantos! (NABUCO, 1886, p.33)

Nabuco utiliza-se do argumento usado por outros autores abolicionistas, qual seja, o de que a abolição da escravidão era uma questão de civilização, de progresso moral da humanidade. Segundo afirma Souza (2011) para Nabuco "não existe a propriedade de um ser humano sobre outro" e que o Direito Internacional não reconhece a nenhum Estado e particular o direito de ter escravos, de modo, que tais pessoas, estrangeiros ou apátridas, se tornam livres ao pisar em solo de um Estado livre.

Desse modo, o raciocínio de Nabuco conclui que, uma vez que as leis brasileiras se submetem às normas internacionais sobre liberdades pessoais, é flagrante a ilegalidade da escravidão no Brasil. O arguto raciocínio jurídico de Joaquim Nabuco trabalha temas da máxima relevância para a afirmação histórica do princípio da dignidade da pessoa humana, o qual pavimentaria a sua construção no campo normativo ao longo do século XX até a sua consagração na Constituição Federal de 1988. Ao reconhecer que um ser humano é um sujeito de dignidade e de direitos, de modo que jamais pode ser convertido em objeto, Nabuco cria uma linha argumentativa tão refinada, que se torna muito difícil contraditá-la de forma válida e racional. 
Ademais, acentua a importância do Direito Internacional, muito antes de fenômenos como a globalização pós-II Guerra Mundial e a criação de Organismos Internacionais como as Nações Unidas ou a OIT. De maneira paradigmática, Nabuco já enxergava, há mais de cem anos, na efervescência cultural da belle époque oitocentista, a importância do Direito Internacional como eixo normativo da comunidade internacional, relativizando, já naquela época, o caráter absoluto do conceito de soberania.

Porém, engana-se quem acredita que Nabuco enxergava na luta contra a escravidão uma questão que se reduzia a isso. Na verdade, concorda-se com a precisa análise de Beiguelman (1982), que defende ser a luta de Nabuco uma forma de incorporar a massa brasileira à economia, de modo que se busca não apenas transcender um instituto jurídico moralmente ignominioso, mas também provocar uma revolução no próprio sistema em que a escravidão se insere (e que poderia prosseguir mesmo após o fỉm da escravidão).

Assim, o pensamento político e a obra de Nabuco alinhavam-se fortemente com a cultura liberal e capitalista da época, sendo uma meta dele transformar o Brasil num país do centro, que se equiparasse ao Reino Unido ou Alemanha, outras potências industriais da época. O Brasil periférico, escravista, "patinho feio" da comunidade internacional, o constrangia e nele despertava a inabalável motivação para fincar no solo da liberdade a bandeira da emancipação dos escravos.

As obras de Nabuco seriam uma referência ímpar para o estudo do período, demarcando fatos, personagens principais e ocorrências históricas. Suas ideias liberais de vanguarda, afinadas ao mais refinado espírito político da época marcam história num Brasil oitocentista marcado pela inconsistência e impropriedade das revoluções liberais, em virtude das raízes coloniais e escravocratas, inexistência de segmentos livres com condições de inserção política e a incompletude da nação como povo unido por vínculos comunitários. Em suam, tudo se dava como decorrência histórica do escravismo e das relações sociais pautadas pela dominação exercida por um restrito círculo de dirigentes e grandes proprietários rurais.

Desse modo, como defende Nogueira (2010 apud OLIVEIRA, 2013), o liberalismo abolicionista proposto por Nabuco visava a despertar uma consciência burguesa na própria sociedade e, para isso era necessário articular o liberalismo político com a questão social, já tão debatida na Europa da segunda metade do século XIX. "Quando a maioria dos liberais [...] 
fechava os olhos para os problemas mais amplos da sociedade, [...], Nabuco operava uma ruptura: exigia a difusão de um novo liberalismo, coerente com os princípios da doutrina e, por isso, aberto a questão social”. (NOGUEIRA, 2010, p. 183).

É por isso que se aduz que enquanto a questão social no mundo europeu no final do século XIX era denunciada pela Igreja e foi o objeto central da Conferência de Berlim de 1890, no Brasil, essa questão social ganhava ares completamente diferenciados. Não representava a superação da dicotomia exploratória da burguesia versus proletariado, refém ainda da omissão de um insensível Estado Liberal. Ao contrário disso, a questão social à brasileira descia às profundezas das estigmatizadas relações humanas e sociais para resgatar o primordial entre os valores que caracteriza a dignidade humana, isto é, o de ser considerado sujeito e não objeto de propriedade.

Nisso repousa precisamente o mérito inestimável da luta e da obra de Joaquim Nabuco. O Brasil, que somente experimentaria algum avanço legislativo e factual de consagração e respeito a direitos trabalhistas décadas depois no Governo Getúlio Vargas, tem em Nabuco um precursor deste movimento.

\section{CONCLUSÃO}

A trajetória política e intelectual de Joaquim Nabuco o coloca, indubitavelmente, no patamar das maiores personalidades do período da Belle Époque. Suas inúmeras obras, capitaneadas por "O Abolicionista" foram decisivas para fomentar no Brasil uma ferrenha crítica à escravidão e o seu ocaso jurídico-institucional em 13 de maio de 1888, após séculos de existência.

Para atingir tal finalidade, Nabuco filiou-se a várias ligas internacionais antiescravistas e, assim, inseriu o Brasil numa rede transnacional de combate à escravidão, tornando-se um broker, por meio da mediação e compartilhamento de recursos e informações. Sua relação deu-se com ingleses, norte-americanos, franceses, cubanos, porto-riquenhos e até filipinos.

Joaquim Nabuco não se reportava às grandes massas populares, pois rechaçava a ideia de um movimento revolucionário. Acreditava que todos os procedimentos que conduziriam o Brasil ao fim da escravidão deveriam tramitar pelas vias estatais, sendo um 
"acordo vindo do alto". Sua agenda política professava a liberdade, condição primária para a restruturação do Estado e da economia que catapultariam o Brasil à condição de grande ator geopolítico mundial.

O liberalismo abolicionista proposto por Nabuco tinha por objetivo romper os grilhões do passado colonial e desenvolver uma consciência liberal e burguesa na sociedade. Desse modo, era necessário articular o liberalismo político com a questão social. Sem libertar o Brasil das amarras escravocratas e feudais, o Brasil jamais se desenvolveria como nação, a ponto de tornar-se uma potência capitalista. Este era o objetivo e realização de Nabuco, que iniciara seu curso em 3 de maio de 1888, com a Lei Áurea.

Todavia, a queda da monarquia e o golpe republicano que se seguiram foram excruciantes para Joaquim Nabuco, pois ele intuiu ser a República incompatível com o ideal de reformas sociais erguidas pelo movimento abolicionista na década de 1880. Ressabiado, retirou-se da cena pública por vários anos, até abraçar novamente a carreira pública e tornarse embaixador do Brasil em Washington em 1905.

Nesta última fase, dedica-se inteiramente à academia, enxergando nos jovens pupilos a forma de eternizar-se, na forma de lições e ensinamentos ao longo de muitas gerações. Devota-se a propor a doutrina de união das Américas ou pan-americanismo.

O conceito de dignidade não é estático. Ele surge no iluminismo de Kant, aquilata a teoria dos Direitos Humanos e certamente evolui em obras como as de Nabuco ao enxergar que escravos são seres humanos e, portanto, sujeitos de direitos e de dignidade. Se hoje consagramos o princípio da isonomia como um pilar fundamental da Constituição Federal isso se deve em parte ao esforço de homens como Nabuco, o qual abnegadamente se devotaram à causa abolicionista. O mesmo se diga com relação ao Direito Internacional, o qual já era invocado por Nabuco no século XIX, como argumento para a afirmação histórica dos Direitos Humanos.

\section{REFERÊNCIAS}

ALONSO, Ângela. O abolicionista cosmopolita: Joaquim Nabuco e a rede abolicionista transnacional. Novos estud. - CEBRAP, São Paulo, n. 88, p. 55-70, dez. 2010. 
. Joaquim Nabuco. São Paulo: Companhia das Letras, 2007

. O americanista tardio: as relações entre o Brasil e os Estados Unidos nos escritos de Joaquim Nabuco. Sinais sociais, Rio de Janeiro, v.9, n.24, p.9-31, jan.-abr. 2014.

BETHELL, Leslie; CARVALHO, José Murilo de. Joaquim Nabuco e os abolicionistas britânicos, Correspondências, 1880-1905. Estudos Avançados, São Paulo, v.23, n.65, p.207229, jan-abr. 2009.

BEIGUELMAN, Paula. Joaquim Nabuco. São Paulo: Ática, 1982.

FALCÃO JÚNIOR, Alfredo Carlos G. "O abolicionismo" e a escravidão: reflexo do pensamento de Joaquim Nabuco nas mudanças legislativas do século XIX. Revista dos Tribunais, São Paulo, ano 101, v.916, p.317-339, fev.2012.

JACKSON, Kenneth David. Um Estadista na academia: Joaquim Nabuco na Universidade de Yale. Estudos Avançados, São Paulo, v.22, n.62, p.335-349, jan-abr. 2008.

LYNCH, Christian Edward Cyril. O Império é que era a República: a monarquia republicana de Joaquim Nabuco. Lua Nova, São Paulo, n. 85, p.277-231, 2012.

NABUCO, Carolina. A vida de Joaquim Nabuco por sua filha Carolina Nabuco. São Paulo: Companhia Editora Nacional, 1928.

NABUCO, Joaquim. O eclypse do abolicionismo. Rio de Janeiro: Leuzinger \& filhos, 1886.

O abolicionismo [online]. Rio de Janeiro: Centro Edelstein de Pesquisas Sociais, 2011. Disponível em: <http://books.scielo.org>. Acesso em 22 ago. 2019.

NOGUEIRA, Marco Aurélio. O encontro de Joaquim Nabuco com a política: as desventuras do liberalismo. São Paulo: Paz e Terra, 2010.

. Nabuco, um diálogo aberto. Novos estud. - CEBRAP, São Paulo, n. 88, p. 3952, nov. 2010 .

OLIVEIRA, Lucas Baptista. Linguagens do abolicionismo no Brasil: a nação no ideário político de Joaquim Nabuco. 2013. 138 f. Dissertação (Mestrado em Filosofia e Ciências Humanas) - Universidade Estadual de Campinas, Campinas, SP, 2013. 
OLIVEIRA, Cecília Helena L. de Salles. Herdeiros e vítimas da "conciliação": política e História em Joaquim Nabuco. Estudos Avançados, São Paulo, v.23, n.65, p.231-244, jan-abr. 2009.

SOUZA, André Peixoto de. Pensamento jurídico brasileiro, ensino do Direito e a Constituição do sujeito político no Império (1822-1891). 2011. 376 f. Tese (Doutorado em Educação) - Universidade Estadual de Campinas, Campinas, SP, 2011. 